\title{
A Study of the Relationship between Type of Dictionary Used and Lexical Proficiency in Writings of Iranian EFL Students
}

\author{
Fereidoon Vahdany (Corresponding Author) \\ Department of English, Payame-Noor University \\ PO Box 19395-3697 Tehran, Iran \\ E-mail: frvahdany@gmail.com \\ Milad Abdollahzadeh \\ MA in English (Linguistics), Pune University, India \\ E-mail:miladabdz@gmail.com \\ Shokoufeh Gholami \\ Department of English, Payame-Noor University \\ PO Box 19395-3697 Tehran, Iran \\ Mahmood Ghanipoor \\ Department of English, Payame-Noor University \\ PO Box 19395-3697 Tehran, Iran
}

Doi:10.7575/aiac.alls.v.5n.6p.31

Received: 01/08/2014

URL: http://dx.doi.org/10.7575/aiac.alls.v.5n.6p.31

Accepted: 25/09/2014

\begin{abstract}
This study aimed at investigating the relationship between types of dictionaries used and lexical proficiency in writing. Eighty TOEFL students took part in responding to two Questionnaires collecting information about their dictionary type preferences and habits of dictionary use, along with an interview for further in-depth responses. They were also asked to write a composition to be evaluated on their lexical proficiency. According to the results, the most frequently used dictionary type was Bilingual (E-P) Desk Dictionary (BDD) and the least favored dictionaries were Bilingual (P-E) Desk Dictionary (BDD2) and Bilingual (P-E) Mobile Dictionary (BMD). Referring to dictionaries in search of meaning during reading-writing, and after speaking-listening were the most common habits of students. Additionally, a significant relationship between the type of dictionary and lexical proficiency in participant's writing was found. There was also a correlation between skill in dictionary use and lexical proficiency in writing. These finding entail some pedagogical benefits to enhance learners' lexical competence by modifying the type of learners' preferred dictionary and their habits in dictionary use.
\end{abstract}

Keywords: Monolingual, Bilingual, Dictionary, Lexical Proficiency, L2, Writing

\section{Introduction}

Today, a good command of English as an international language is essential for better functioning in both career and life. Although learners are increasingly attending English classes to fulfill this dream, English teachers are mostly unavailable outside these classes. Therefore, learners need to find a reliable source to refer to when they encounter a variety of problems related to learning English as a second language. Several studies (Walz, 1990; Ryu, 2006; Cubillo, 2002) have demonstrated that dictionaries as a reliable source that provides learners with useful linguistic and cultural information, especially in out of class settings when learners are responsible for their own learning. The role of dictionaries in language learning is evident since the first thing a foreign language learner usually purchases is a dictionary (Baxter, 1980). Huang (2003) considered dictionaries as useful, fairly common and even necessary tools in language acquisition by EFL learners. It is as an essential source, if not the main source, of information on language for all literate persons who have questions on form, meaning, and/or use of a word(s) in their L1 or in another language (Kirkness, 2004, p. 54-81). It seems that the conviction of the usefulness of dictionaries is common among lexicographers, and also language learners themselves. However, as far as language teachers are concerned, various perspectives have been observed on the issue. Some believe that dictionaries are lexically beneficial, while others are concerned that the consultation process is distracting and might upset the learning process (Hosenfeld, 1977). On the other hand, lexical aspect is an area of potential problem for L2 writers, and vocabulary plays an important role both in the writing process and the comprehensibility of the final writing product. According to Baba (2009), Lexical proficiency as a cognitive construct is one of the various language abilities and knowledge that is called on L2 writing. Meara (2005) divided lexical proficiency into two aspects, which are breadth of knowledge features (i.e. how many words a learner knows, also called vocabulary size) and depth of knowledge features (i.e. how well a learner knows a 
word and also how this knowledge of words is structured in his mind). In a similar approach to vocabulary, Engber (1995) focused in his study on "breadth" of lexical proficiency and simultaneously "productive" vocabulary knowledge.

One of the strategies used for solving lexical problems during writing is dictionary use. However, there have been few studies showing the effect of using dictionaries on the lexical proficiency in writing ability of EFL students. Therefore, the results of the studies on the effect of dictionary use habits on lexical proficiency in writing would be of considerable concern to both teacher trainers and language teachers who are trying everything at their disposal to improve L2 learner's writing skills.

\subsection{Review of Literature}

One of the important decisions in every study on dictionary has always been the classification of dictionaries. According to Al-haysony (2011) different criteria can be used to classify dictionaries. They can be classified according to language (monolingual, bilingual, or bilingualized), according to variety of language (British English, American English) or according to the medium through which dictionaries are presented and accessed(paper, On-line, electronic, etc.). Additionally, other criteria such asproficiency level and dictionary size can be used to classify dictionaries. Bilingual dictionaries are the most frequently used dictionary type among EFL learners with different proficiency level especially at the initial stages (Kent, 2001; Kharama, 1985; Schmitt, 1997; Tomaszcyk, 1979) and Monolingual dictionaries are rather infrequently used (Baxter, 1980; Tomaszcyk, 1979).Hartmann (1994) classified bilingualized dictionaries as a sub-type with hybrid features of a bilingual dictionary produced for EFL learners and a monolingual dictionary produced for native speakers. Laufer (1997, p.361) defined it as "a dictionary that contains the monolingual information about a word and its translation into the learner's mother tongue". Raudaskoski (2002) defined bilingualized dictionary as "supposedly happy marriage of the two mentioned paradigms for monolingual and bilingual dictionaries. It contains the L2 definitions and examples of the monolingual dictionary and the easy-to-use L1 equivalents of the bilingual dictionary. The emphasis in the entries is on the L2 material, and for this reason the equivalents are often called "keys", as they are rather aids for understanding than stand-alone translations of the headword. The user is supposed to turn the definitions and examples first, and if the meaning of the headword still remains somewhat unclear, the key is there to provide clarification and reassurance. ....in short, the bilingualized dictionary can be seen as an all-in-one solution to the needs of a learner's dictionary users "(p.2).

The first pioneering research on dictionary use was done by Barnhart (1962). In this research, questionnaires were distributed among the teachers to have their freshman students rate 6 types of information offered by American college dictionaries. This research was especially important because its results helped lexicographers decide what to include in dictionaries. Tomaszczyk's (1979) study has also its famous contribution to dictionary use research in the 1970s. The aim of this study was to better recognize the dictionary needs of learners and translators. The results indicated that meaning and spelling were of greater importance as motives for dictionary search than etymology and also students preferred the bilingual dictionaries over monolingual ones.

There is a controversy between the students and the teachers about the choice between monolingual and bilingual dictionaries. According to Baxter (1980); Atkins and Knowles (1990) most of the students prefer a bilingual to a monolingual dictionary and also the electronic format to the printed one because both of these preferences enable them to find the meaning quickly and almost effortlessly.

According to White (1997) unskilled dictionary users may rely mostly on the L1 information and as L1 concepts do not always map neatly onto target language's concepts or vice versa, so students relying on L1 information may aggregate the influence of mother tongue by the presence of L1 translation and this mother tongue influence is considered as a major cause of learners' errors in second language acquisition. On the other hand, as Laufer and Melamed (1994) found some good dictionary users may find L1 translation useful and try to reinforce their decisions about the meaning and usage of new word.

In another related study, Lew (2000) asked Polish EFL learners with different proficiency level to rate monolingual and bilingual dictionaries. The results showed significantly higher ratings for monolingual than bilingual dictionaries. Ard (1982) studied the use of bilingual dictionaries by ESL students in high-intermediate-level writing class and concluded that the use of bilingual dictionary induced some students' writing errors and this was related to the semantic differences between L1 and L2

Laufer and Hadar (1997) studied the effect of three types of dictionaries (monolingual, bilingual, and bilingualized) on comprehension and production of new words by EFL learners and concluded that three types of dictionaries had different effects with individual dictionary users. For comprehension, all learners using bilingualized dictionary received the best scores. Unskilled learners benefited more from bilingual dictionary and average and good learners benefited more from monolingual ones. For production, monolingual dictionaries and bilingualized dictionaries yielded the highest score and monolingual dictionaries were the second best. The differences among the dictionaries were not statistically significant.

Chan (2011) also studied the learners' preference with regard to bilingualized versus monolingual dictionaries. A total number of 169 advanced ESL learners who were majoring English at two local universities took part in his study. He used a questionnaire which was designed to obtain information about their dictionary habits and preferences. That was a self-explanatory questionnaire which participants could complete in about 15-25 minutes. Fourteen students who participated in the survey also took part in three focus group interviews_group 1 with monolingual dictionary use, group 2 with bilingualized dictionary use, and group 3 with both monolingual and bilingualized dictionary use, for one hour. 
Results showed that there were some misconceptions about bilingualized dictionaries, especially about the alleged lack of definitions and usage information. Engber (1995) on his study on the relationship of lexical proficiency to the quality of ESL composition concluded that compositions with wider variety of words were rated significantly higher than the compositions with narrower variety of words.

In conclusion, it seems that all studies point to the fact that dictionary type as well as dictionary use habits contribute to students' language skills especially their writing proficiency, although this contribution depends on learners' level of English, type of language skill, and their conception of dictionary use.

\subsection{Research questions and hypotheses}

This study seeks to answer the following questions:

1. Is there a significant relationship between the type of dictionary used by Iranian upper-intermediate language learners and their lexical proficiency in writing?

2. Is there a significant relationship between Iranian upper-intermediate language learners'skill in dictionary use and their lexical proficiency in writing?

According to the aforementioned research questions, the following null hypotheses have been formulated:

H01 There is not significant correlation between the type of dictionary used by Iranian upper-intermediate language learners and their lexical proficiency in writing

H02 There is not significant correlation between Iranian upper-intermediate language learners' skill in dictionary use and their lexical proficiency in writing?

\section{Methodology}

This study has a quasi-experimental design. It was conducted to investigate Iranian EFL learners' preferences and their habits for dictionary use. To achieve this objective, three main research tools were used- namely two questionnaires, interviews, and a task. This type of design, that uses different research methods to investigate the same issue, is called a triangulation mixed method design (Creswell, 2002). The need for triangulation arises from the ethical need to confirm the validity and reliability of the process. In addition, using multiple methods in a research design would also help to give a fuller picture and address many different aspects of phenomena.

\subsection{Participants}

In total, eighty Iranian TOEFL students at upper- intermediate level who were randomly selected from three language institutes in Ghaemshahr, Iran, participated in this study. They were both males and females and their age ranged from 19 to 45.All participants had already passed at least one course in English. For the interview section of the study, eighteen participants were interviewed to gain more insights with regard to their responses on the questionnaires.

\subsection{Instruments and Data Collection Procedures}

Two questionnaires were used in the present study: Questionnaire I, Questionnaire II. After checking the reliability of both questionnaires, questionnaire (I) was conducted to collect some quantitative data about participants' preferences in using dictionaries. Questionnaire II was used to identify dictionary habits of the learners. An open ended interview was also conducted to solicit in-depth responses on learners' choice of dictionaries. In the following sections, the materials used in this study will be presented in more details.

\subsubsection{Questionnaire I}

In order to collect some quantitative data about participants' preferences in using dictionaries, Questionnaire I was prepared. To avoid any possible misinterpretation and impression judgment, this questionnaire was coded. The questions were self-explanatory. This questionnaire consisted of two sections: the first section needed information about the participants, such as their age, years of language learning, gender and level of the dictionary they use; the second section included questions related to frequency of use of different kinds of dictionaries which required the respondents to choose from 1-4 on a Likert scale, from the four options never, sometimes, usually, always.

\subsubsection{Interview}

Among the participants who completed Questionnaire I, eighteen students interviewed to solicit in-depth responses on learners' choice of dictionaries. The purpose was to collect more specific details about the dictionary they use. Selecting the students for the interview was based on a criterion; 6 participants from monolingual used group and 6 from bilingual (L1-L2) used group and 6 from bilingual (L2-L1).

\subsubsection{Questionnaire II}

A detailed questionnaire will be used with more detailed questions about the learner' dictionary habits. To avoid any possible misinterpretation and impression judgment, this questionnaire was also coded. The questions were selfexplanatory. It consisted of the items related the learners' habits on dictionary use that required the respondents to choose from 1-4 on a Likert scale, from the four options never, sometimes, usually, always. The first twelve items were related to the frequency of dictionary use during language skills, the other questions were about the importance of information in the dictionaries for learners and the frequency of theirs use. 


\subsubsection{Task}

Skill in dictionary use was tested by a task in which the participants used their dictionary to answer some questions related to word usage. Participants were asked to use relevant parts of Oxford Advanced Learners which were copied and distributed to all of them. This task consisted of four exercises related to the knowledge of word labels (their usage and meaning), knowledge of word definition, knowledge of grammatical patterns, and knowledge of parts of speech.

\subsubsection{Composition}

In order to investigate the possible relationship between dictionary use preference and lexical proficiency in writing, twenty participants were asked to write a composition on the same topic titled "some people think that automobile has improved modern life. Others think that automobile has caused serious problems. What is your opinion? Use specific reasons and give examples to support your answers". Their time limit for this writing was 30 minutes.

As it was mentioned in the introduction section, a common point among all the proposed frameworks for lexical proficiency was that it should consist of two dimensions: vocabulary breadth or size (the number of words each one knows) and depth, or quality (knowledge of various aspects of a word). In this study, Lexical Proficiency in writing refers to the participants' skill in using words correctly and appropriately in writing. In order to measure lexical proficiency, a rating scale was developed in which the following features were considered:

1. Syntax: including parts of speech, grammatical pattern, etc.

2. Semantics: related to word denotation

3. Pragmatics: related to appropriate context of use

4. Collocation: words going together

5. Morphology: correct suffixes and prefixes

6 . Variety and avoiding unnecessary repetition.

\subsection{Data Analysis procedures}

Cronbach's alpha statistics was calculated for Questionnaire I and II items to estimate the reliability index for the questionnaires. The quantitative data from these two questionnaires was analyzed using SPSS version 16 to obtain descriptive and inferential statistical results to determine type of dictionary and also habits in dictionary use. The means, frequencies, and standard deviation of data were calculated. The analysis of the qualitative data obtained from the interview involved transcribing, categorizing and summarizing the data. As far as rating the compositions were concerned, inter- rater reliability for the two primary raters of the compositions which were scored based on a predetermined criteria were examined through running Pearson product-moment correlation. After examining the correlation between the two raters' scores, the total score for each sample was to bethe mean of them.

In order to investigate the possible relationship between type of dictionary used and lexical proficiency in writing of TOEFL students, Chi square test and Eta test were used. Attention was paid to the relationship between type of dictionary used and lexical proficiency of the participants in composition in order to test the first Hypothesis and to provide statistical insight into the relationship between these two variables (dictionary type and composition proficiency). Additionally, in order to examine the possible differences between the participants who use different types of dictionaries regarding their lexical proficiency, One Way ANOVA was run to the results of the lexical proficiency test. Examining the second null hypothesis was achieved through a Pearson correlation test which was run to the results of the task scores and the lexical proficiency scores.

\section{Results and Discussion}

\subsection{Descriptive Statistics}

Descriptive statistics were used in order to determine participants' preferences in using dictionaries and also the learners' dictionary habits. Table 1 summarizes the statistics that were obtained from Questionnaire I and shows the participants' preferred dictionaries. As it can be seen in Table 1, the use of Bilingual (E-P) Desk Dictionary (BDD) has the highest mean $(\mathrm{M}=2.50)$, followed closely by the Use of Monolingual Desk Dictionary (MDD) $(\mathrm{M}=2.25)$. The use of Bilingual (P-E) Desk Dictionary (BDD2), and use of Bilingual (P-E) Mobile Dictionary (BMD) have considerably lower mean $(\mathrm{M}=1.70)$. In addition, Items $(2=$ Monolingual Computer Dictionary $(\mathrm{MCD}))$, (6= Bilingual (E-P) Mobile Dictionary (BMD)), (7= Bilingual (P-E) Desk Dictionary (BDD2), and (9= Bilingual (P-E) Mobile Dictionary (BMD) were the cases which nobody reported to make use them repeatedly or on all occasions.

Table 1. Descriptive Statistics (Questionnaire 1)

\begin{tabular}{|c|c|c|c|c|c|c|c|}
\hline & $\begin{array}{l}d 0 \\
\vdots \\
\vdots \\
\frac{1}{2}\end{array}$ & 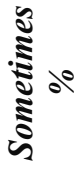 & 离 & 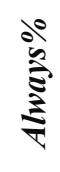 & 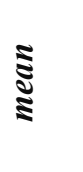 & ถิ & $\stackrel{\Sigma}{\Sigma}$ \\
\hline $\begin{array}{l}\text { 1.Use of Monolingual Desk } \\
\text { Dictionary(MDD) }\end{array}$ & 20 & 40 & 35 & 5 & 2.25 & .83 & 180 \\
\hline $\begin{array}{l}\text { 2. Use of Monolingual Computer } \\
\text { Dictionary(MCD) }\end{array}$ & 40 & 20 & 40 & 0 & 2 & .90 & 160 \\
\hline $\begin{array}{l}\text { 3.Useof Monolingual Mobile } \\
\text { Dictionary(MMD) }\end{array}$ & 50 & 10 & 10 & 30 & 2.20 & 1.33 & 176 \\
\hline
\end{tabular}




\begin{tabular}{lccccccc}
\hline $\begin{array}{l}\text { 4.use of Bilingual (E-P) Desk } \\
\text { Dictionary(BDD) }\end{array}$ & 20 & 30 & 30 & 20 & 2.50 & 1.03 & $\mathbf{2 0 0}$ \\
\hline $\begin{array}{l}\text { 5.use of Bilingual (E-P) Computer } \\
\text { Dictionary(BCD) }\end{array}$ & 30 & 40 & 20 & 10 & 2.10 & .94 & $\mathbf{1 6 8}$ \\
\hline $\begin{array}{l}\text { 6.use of Bilingual (E-P) Mobile } \\
\text { Dictionary(BMD) }\end{array}$ & 50 & 30 & 20 & 0 & 1.90 & 1.14 & $\mathbf{1 5 2}$ \\
\hline $\begin{array}{l}\text { 7. Use of Bilingual (P-E) Desk } \\
\text { Dictionary(BDD2) }\end{array}$ & 50 & 30 & 20 & 0 & 1.70 & .78 & $\mathbf{1 3 6}$ \\
\hline $\begin{array}{l}\text { 8. Use of Bilingual (P-E) } \\
\text { Computer Dictionary(MCD2) }\end{array}$ & 50 & 10 & 30 & 10 & 2 & 1.10 & $\mathbf{1 6 0}$ \\
\hline $\begin{array}{l}\text { 9. Use of Bilingual (P-E) Mobile } \\
\text { Dictionary(BMD2) }\end{array}$ & 50 & 30 & 20 & 0 & 1.70 & .70 & $\mathbf{1 3 6}$ \\
\hline
\end{tabular}

Questionnaire II also provided some valuable results. A look at the mean scores of the groups showed that habits like referring to find meaning and importance of word definition yielded the highest mean $(\mathrm{M}=3.40)$. Importance of example sentence and importance of grammatical pattern or features achieved the second best result with the mean of $(M=3.20)$, and dictionary use before listening had the lowest mean $(\mathrm{M}=1.40)$. Forty percent of the respondents reported that they always use dictionaries while reading and $60 \%$ of them claimed that they never use dictionaries before listening. In addition, $50 \%$ of the participants reported that they never use them while speaking. The meaning of a word as a translation equivalent was reported to be sought more often than the pronunciation or cross comparison. On the other hand, use of dictionary in situations like before reading, after writing, while speaking, and before listening was not frequent events.

According to the interview results, most students used dictionary to find meaning and definition of a word in Persian. This is in line with what was discovered in other key studies on dictionary use where subjects mostly checked their dictionaries for the meanings of words and findings the definitions of the words (Tomaszczyk, 1979; Alqahtani, 2005).

3.2Inferential Statistics

In order to find the relationship between the type of dictionary used and lexical proficiency in writing, a chi- square Test along with Eta Test was used. Tables 2 and 3 present the results of chi-square and Eta test respectively.

Table 2.Chi-square Test for Correlation between Type of Dictionary and Lexical Proficiency

\begin{tabular}{llll}
\hline & Value & df & Asymp. Sig. (2 sided) \\
\hline Pearson Chi-Square & 76.042 & 40 & .001 \\
N of Valid Cases & 20 & &
\end{tabular}

The two-sided asymptotic significance of the chi-square statistic was lower than 0.05 , so it is safe to say that the relationship between type of dictionary used and lexical proficiency was not due to chance, which implies that use of each type of dictionary lead to different levels of lexical proficiency. The significance value of the test is 0.001 . Since this value is less than 0.05 , it can be concluded that the relationship observed in the cross-tabulation is real and not due to chance and thus the first null hypothesis is rejected.

Table 3. Eta test for correlation between type of dictionary and lexical proficiency

\begin{tabular}{llll}
\hline Directional Measures & & \\
\hline & & \multicolumn{2}{c}{ Value } \\
\hline Nominal by Interval & Eta & lexical proficiency Dependent & .969 \\
\cline { 3 - 4 } & & Type of dictionary Dependent & .772 \\
\hline
\end{tabular}

In order to examine the possible difference between the participants who use different types ofdictionaries regarding their lexical proficiency, One Way ANOVA was run to the results of the lexical proficiency test.As table 4 demonstrates, the results indicated significant difference between the participants who used specific types of dictionaries in terms of their lexical proficiency. The significance of the F value in the ANOVA table is 0.000 . Thus, it can be concluded that there is a significant difference among the means of the participants in lexical proficiency test.

Table 4. The Results of One Way ANOVA Test.

\begin{tabular}{llllll}
\hline & Sum of Squares & df & Mean Square & F & Sig. \\
\hline Between Groups & 166.769 & 5 & 33.354 & 42.571 & .000 \\
Within Groups & 10.969 & 14 & .783 & & \\
Total & 177.738 & 19 & & & \\
\hline
\end{tabular}


Pearson correlation test was run to the results of the task scores and the lexical proficiency scores in order to find out whether there was a correlation between skill in dictionary use and lexical proficiency in writing. Table 5 presents the result of Pearson correlation test.

Table 5. Correlation between the Skill Task and Lexical Proficiency

\begin{tabular}{llll}
\hline & & Lex.pro & Task \\
\hline Lexical proficiency & Pearson Correlation & 1 & $.958^{* *}$ \\
& Sig. (2-tailed) & .000 \\
& $\mathrm{~N}$ & 20 & 20 \\
Task & Pearson Correlation & $.958^{* *}$ & 1 \\
& Sig. (2-tailed) & .000 & \\
& $\mathrm{~N}$ & 20 & 20 \\
\hline
\end{tabular}

The Pearson correlation coefficient measured the linear association between these two scale variables (task scores and lexical proficiency in writing). The correlation reported in the table is (.958), and is statistically significant because the p-value of 0.00 is lower than 0.05 . This rejects the second null hypothesis and suggests that there is a significant relationship between the task and lexical proficiency.

\subsection{Discussion}

This study attempted to identify the dictionary use preferences of Iranian EFL students. The aim was to investigate not only the preferences but what type of dictionary is the most frequently used in different learning situations. It has been found that the majority of students reported using Bilingual (E-P) Desk Dictionary (BDD) more frequently than any other type of dictionary reported in the study. Analysis of data gathered revealed students' willingness to use bilingual dictionaries more than monolingual ones which support similar findings of other studies (Tomaszczyk, 1979; Baxter, 1980). In addition, it was found that in terms of medium of dictionary, the desk E-P dictionary was reported to be used more often than any other types of dictionary. Apparently, quick and easy search capabilities, and the psychological security of using L1 in order to better understand dictionary content played an important part in the participants' choices. On the other hand, a minority of students reported that they prefer to use mobile dictionaries. The results of the descriptive statistics showed that there are differences between the respondents' preferences, but the use of Bilingual (EP) Desk Dictionary (BDD) seems to be more favored than the other ones. Bilingual (P-E) Desk Dictionary (BDD2) and Bilingual (P-E) Mobile Dictionary (BMD2) were the least favored dictionaries reported by the respondents.

Data obtained from the second questionnaire suggested that looking up the meaning of words and definition of words were the main purposes of dictionary use. Since one of the main functions of dictionaries is to provide word meaning, it is clear that L2 learners consult dictionaries most frequently for this purpose. On the other hand, the dictionary information which was reported to be used least was using dictionary before listening (mean=1.40).As expected from the high use of E-P , using a dictionary to find meaning and definition of a word in Persian, obtained a mean frequency far higher than that of any other situations with a mean of 3.40 and SD of .67. This is in line with what was discovered in other key studies on dictionary use where subjects mostly checked their dictionaries for the meanings of words and findings the definitions of the words (Tomaszczyk, 1979; Alqahtani, 2005).

With regard to the first research question, Eta measure of association with a value equal to .77 close to 1 indicated a high degree of association between the type of dictionary used and lexical proficiency scores. The findings showed that monolingual dictionaries as well as bilingual (L1-L2) and bilingual (L2-L1) dictionaries were all useful tools for guiding language learners through looking up the relevant lexical or semantic information and thus learning new vocabulary in this study. However, the degree of usefulness was different in terms of their effect on foreign language vocabulary learning. Monolingual users seemed to benefit more from lexical information provided and thus improved their lexical proficiency. It seems that using monolingual dictionaries will provide more elaborate and precise information about the word than using bilingual dictionaries. However, it should be noted that the significant relationship observed between types of dictionary used and lexical proficiency does not necessarily mean that bilingual dictionaries were more useful than monolingual or bilingulized ones. As far as the second research question is concerned, Pearson correlation confirmed the strength and direction of the association between skill in dictionary use and lexical proficiency in writing. Lexical proficiency of the participants were measured by a rating scale which included some features such as syntax, semantics, pragmatics, collocation, morphology, and variety and avoiding unnecessary repetition. It is quite obvious that lexical knowledge and skill in dictionary use are important for successful foreign language learning. The results of the Pearson correlation depicted significant relationship between the task which was used to measure the skill in dictionary use and the participants' lexical proficiency. The results of the present study are consistent with other studies which claim that measures of lexical proficiency in learners' written texts have been shown to relate well to the skill in dictionary use (e.g. Laufer and Hadar, 1997). They showed that skilled dictionary users could benefit from the 
information available in different types of dictionaries and improved their lexical knowledge. The high amount of correlation between skill in dictionary use and lexical proficiency was statistically significant for the present study. This also supports Laufer and Hadar's results who confirmed that "the good dictionary users can benefit from different dictionaries and enhance their lexical knowledge (Laufer and Hadar, 1997, p. 195).

\section{Conclusions}

\subsection{Summary}

According to the data obtained from the Questionnaire I, the most frequently used dictionary type among upperintermediate students at Ghaemshahr Language Institutes was Bilingual (E-P) Desk Dictionary (BDD) and the least favored dictionaries were Bilingual (P-E) Desk Dictionary (BDD2) and Bilingual (P-E) Mobile Dictionary(BMD).Schematically, the results can be represented as follows:

\section{Bilingual (L2-L1) Dictionary > Monolingual Dictionary >Bilingual (L1-L2) Dictionary}

The results of Eta test showed that there was a significant relationship between the type of dictionary used and lexical proficiency suggesting that the use of each type of dictionary results in different levels of lexical proficiency. Additionally, data obtained from Questionnaire II indicated that referring to dictionaries to find out meaning was the most common habit of advanced students. Importance of example sentence and importance of grammatical pattern or features were the second common habits among advanced students. When reading was concerned, most students used dictionary while reading and dictionary use before reading was the least common habits. Considering writing skill, using dictionaries while writing was among the most common habits, and dictionary use after writing was the least common habits reported.

Dictionary use after speaking was the most common and dictionary use while speaking was the least common habits in relation to dictionary use in speaking skill. Use of dictionary after listening and dictionary use before listening were the most and the least common habits in regard to listening skill. Use of dictionary in situations like before reading, after writing, while speaking, and before listening, did not frequently happened. Based on the results of the Pearson Correlation Test, it was also found that there was a significant correlation between skill in dictionary use and lexical proficiency in writing. While the majority of the participants in this study were satisfied with general meaning of words obtained from English- Persian desk dictionaries, a few number tended to make sure that the target word they intend to use has the exact meaning they want to express and thus preferred monolingual dictionaries. This implies that Iranian EFL learners are not either aware of the advantages of monolingual dictionaries or they don't have a tendency for using monolingual dictionaries instead of widespread use of bilingual dictionaries.

\subsection{Pedagogical Implications}

The findings of the study revealed that EFL learners have a variety of dictionary use preferences and habits and will inform EFL teachers of dictionary use habits and preferences of EFL learners, the reasons underlying their choices, and the difficulties that learners may experience during use of different types of dictionaries and appropriate dictionary for solving lexical problems during writing.EFL teachers should familiarize their students with dictionary properties and the information it provides about each word. The distinction between different kinds of dictionaries should also be clear for the students. By suggesting an appropriate dictionary type, teachers can help their students to improve their lexical proficiency as effectively as possible and enhance their EFL writing. Moreover, using suitable dictionary types, students will be able to learn new entries quickly and thus improve their writing skill. This also increases students' abilities in comprehension and production of unknown words, and makes them more efficient EFL learners. The present study provides guidance for teachers in the hope that they will make useful contributions to the issue of dictionary use in foreign language situation like Iran. In general, dictionaries can serve as a means of checking the correctness of the guesses made, implanting the correct meanings in the learners' memories, and consequently fostering the process of vocabulary learning.

\subsection{Suggestions for Further Research}

Similar related studies can be done on other proficiency levels, namely elementary and intermediate EFL learners. In order to have a comprehensive picture of the relationship between skill in dictionary use and EFL learners' lexical proficiency, researchers can also replicate the study with different types of tasks which include more aspects of dictionary use skills. Further studies could also be concerned with focusing on the usefulness of dictionary types and reasons for user failure when using specific type of dictionaries. Additional studies could investigate whether there is a significant difference between male and female in terms of their dictionary use habits.

\section{References}

Alhaysony. M. (2011).Dictionary Look-Up Behavior of Saudi Female EFL Students. European Journal of Social Sciences. 26 (2) pp. 250-267.

Al-qahtani, M. (2005), The use of vocabulary learning strategies by EFL learners at three different educational levels. Unpublished PHD thesis, University of Essex.

Ard, J. (1982) .The use of bilingual dictionaries by ESL students while writing. ITL Review of Applied Linguistics, 58: 1-27. 
Atkins, B.T. \& Knowles, F.E. (1990). Interim report on the EURALEX/AILA Research Project into Dictionary Use. In I. Magay \& J. Zigany (Eds.), Buda LEX 88 Proceedings. Budapest: AkadémiaiKiadó, 381-392.

Baba, K. (2009).Aspects of lexical proficiency in writing summaries in a foreign language. Second Language Writing, 18, 191-208.

Barnhart, C. L. (1962). Problems in editing commercial monolingual dictionaries.In Problems in Lexicography, Householder, F.W. Bloomington: Indian University. Sol Saporta (eds.), 161-181.

Baxter, J. (1980). The dictionary and vocabulary behavior: a single word or a handful? TESOL Quarterly, 14 (3), 325-336.

Chan . A. Y. W. (2011). Bilingualised or monolingual dictionaries? Preferences and practices of advanced ESL learners in Hong Kong. Language, Culture and Curriculum. 24(1), 1-21.

Creswell, J.W. (2002). Research design: Qualitative, quantitative, and mixed methods approaches. New York: Sage Publications.

Cubillo, M. (2002). Dictionary Use and Dictionary Needs of ESP students: An experimental approach. International Journal of Lexicography. 15(2), 206-228.

Engber,C.A. (1995). The relationship of lexical proficiency to the quality of ESL compositions. Journal of second language writing,4, 139_155.

Hartmann, R.R.K. (1994). Bilingualized versions of learners' dictionaries. Fremdsprachen Lehren und Lernen, 23, 206-220.

Hosenfeld, C. (1977) .A preliminary investigation of the reading strategies of successful and non-successful second language learners. System 5: 110-123.

Huang, D. (2003). Taiwanese university English majors' belief about English dictionaries and their dictionary strategy use. Unpublished PhD, University of Texas at Austin.

Kent, D. (2001). Korean university freshmen's' dictionary use and perceptions regarding dictionaries. The Korean TESOL journal. Vol. 4, No. 1

Kharma, N.N. (1985). Wanted: a brand-new type of learners' dictionary.Multilingua.4, 8590.

Kirkness, A. (2004).Lexicography. In A. Davies \& C. Elder (Eds.), The handbook of applied linguistics. Oxford, England: Blackwell Publishing.

Laufer, B. (1997). The lexical plight in second language acquisition: Words you don't know, words you think you know, and words you can't guess. In J. Coady \& T. Huckin (Eds). Second language vocabulary acquisition (pp. 20-34) New York: Cambridge University Press.

Laufer, B., \&Hadar, L. (1997).Assessing the effectiveness of monolingual, bilingual, and ' bilingualised' dictionaries in the comprehension and production of new words. The Modern Language Journal, 81(2),189-196.

Laufer,B. , \&Melamed, L.(1994). Monolingual and bilingualised dictionaries: which are more effective, for what and for whom. In W. Meijs, M. Moerland, E. ten Pas, P.van Sterkenburg, \& P. Vossen(Eds.), EURALEX'94 proceedings (pp. 565-576). Amsterdam: New University.

Lew, R. (2000). How do Polish learners of English rate bilingual and monolingual dictionaries? Retrieved October 21, 2000 from: http://scholar.google.com/scholar.

Meara, P. (2005). Lexical frequency profiles: A Monte Carlo analysis. Applied Linguistics, 26, 32-47.

Raudaskoski, S. ( 2002). Translation, the key or equivalent? A study of the dictionary use strategies of Finnish senior secondary school students. Kernerman Dictionary News, 10.

Ryu, J. (2006). Dictionary Use by Korean EFL College Students, Language \& Information Society 7, 83-114.

Schmitt, N. (1997). Vocabulary learning strategies. In N. Schmitt \& M. McCathy (Eds.), Vocabulary: Description, acquisition and pedagogy. Cambridge: Cambridge University Press.

Tomaszczyk, J. (1979). Dictionaries: users and uses. Glottodidactica, 12, 103-119.

Walz, J.(1990). The dictionary as a secondary source in Language Learning. The French Review, 64(1), 79-94.

White, P.A. (1997). The role of dictionaries in language learning. Dialog on Language Instruction, 12(1-2), 7-16. 